\title{
Low-dose radiotherapy for painful osteoarthritis of the elderly: A multicenter analysis of 970 patients with 1185 treated sites
}

\author{
Alexander Rühle1,2,3 • Elisabeth Tkotsch' • Rainer Mravlag ${ }^{4}$ Erik Haehl1,2 Simon K. B. Spohn1,2 .

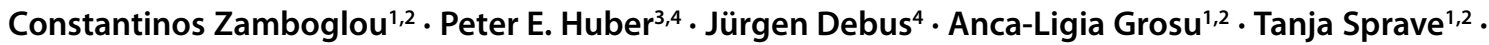 \\ Nils H. Nicolay ${ }^{1,2,3}$ iD
}

Received: 18 May 2021 / Accepted: 1 July 2021 / Published online: 3 August 2021

(c) The Author(s) 2021

\begin{abstract}
Purpose Painful osteoarthritis is common in elderly patients, and low-dose radiotherapy has been demonstrated to provide effective symptomatic treatment. We examined the analgesic effects of low-dose radiotherapy for osteoarthritis in the elderly aiming to reveal potential differences in the response rates relating to increasing age.

Methods A retrospective analysis was performed at two university hospitals including elderly patients ( $\geq 65$ years) undergoing radiotherapy for osteoarthritis between 2008 and 2020. Pain intensity and response were quantified using the numerical rating scale (NRS) and the Pannewitz score. Age groups were defined for young old (65-74 years), older old (75-84 years), and oldest old patients ( $\geq 85$ years).

Results In all, 970 patients with 1185 treated sites and a median age of 76 years were analyzed. Mean NRS was 66 at baseline ( $\mathrm{t} 0), 53$ after radiotherapy ( $\mathrm{t} 1)$, and 44 at first follow-up ( $\mathrm{t} 2)(p<0.001$ for $\mathrm{t} 0-\mathrm{t} 1, \mathrm{t} 1-\mathrm{t} 2$, and $\mathrm{t} 0-\mathrm{t} 2)$. At $\mathrm{t} 1,1.5 \%$ exhibited a Pannewitz score of 0 (no pain), 58.5\% of 1-2 (less pain), 36.1\% of 3 (equal pain), and 3.9\% of 4 (worse pain), while at $\mathrm{t} 2$, pain response shifted towards $6.9 \%(0), 58.6 \%(1-2), 28.1 \%$ (3), and $6.3 \%$ (4). Pain response did not differ between age groups at $\mathrm{t} 1(p=0.172)$ or $\mathrm{t} 2(p=0.684)$. In addition, pain response after re-irradiation $(n=384$ sites $)$ was $61.0 \%$ and was comparable between age groups $(p=0.535)$.

Conclusion Low-dose radiotherapy results in pain reduction in about two-thirds of treated sites with no difference relating to increasing age, showing that radiotherapy is an effective analgesic treatment for osteoarthritis even at advanced ages.
\end{abstract}

Keywords Low-dose radiotherapy $\cdot$ Elderly patients $\cdot$ Osteoarthritis $\cdot$ Joint disorder $\cdot$ Benign diseases

\section{Introduction}

1 Department of Radiation Oncology, University of Freiburg-Medical Center, Robert-Koch-Str. 3, 79106 Freiburg, Germany

2 German Cancer Consortium (DKTK) Partner Site Freiburg, German Cancer Research Center (DKFZ), Neuenheimer Feld 280, 69120 Heidelberg, Germany

3 Department of Molecular Radiation Oncology, German Cancer Research Center (DKFZ), Neuenheimer Feld 280, 69120 Heidelberg, Germany

4 Department of Radiation Oncology, University Hospital Heidelberg, Im Neuenheimer Feld 400, 69120 Heidelberg, Germany
Osteoarthritis is a common disease especially in the elderly that is becoming more frequent in developed countries due to an increasing life expectancy [1]. Osteoarthritis is the most frequent joint disease in adults globally, and about one in three adults exhibits radiological signs of osteoarthritis $[2,3]$. Considering the reduction of health-related quality-of-life in affected patients, the considerable socioeconomic costs due to multiple therapeutic procedures, and the secondary complications, e.g., opioid abuse, psychological disorders, physical inactivity and thereby increased risk for obesity and cardiovascular diseases, osteoarthritis has a huge impact on the health systems [4-7]. There are several therapeutic options with varying treatment intensity including physical therapy, nonsteroidal anti-inflammatory drugs (NSAIDs), intraarticular corticosteroid or hyaluronic 
acid injection and surgical procedures such as joint replacements or arthrodesis [8].

Due to the anti-inflammatory effects of small doses of ionizing radiation, low-dose radiotherapy is commonly used in patients with painful osteoarthritis, especially in central and Eastern Europe [9]. The advantages of low-dose radiotherapy include the noninvasive nature, the cost-efficacy, and the near absence of toxicities. As the risk for radiationinduced tumors using low radiation doses is very low and further reduced in elderly patients, low-dose radiotherapy for osteoarthritis is an attractive treatment in this cohort [10, 11]. The anti-inflammatory effect of low-dose radiotherapy has been shown to be mediated by several effects such as the modulation of expression of endothelial cells' adhesion molecules, cytokine release by leukocytes and nitric oxide production by macrophages [12-16]. Furthermore, lowdose radiotherapy was found to positively influence bone metabolism by increasing osteoblast-induced mineralization and decreasing RANK-L levels [17].

A plethora of studies have reported analgesic effects of low-dose radiotherapy for osteoarthritis, but these studies mostly did not focus on the important subgroups of elderly patients [18-25]. Nevertheless, there are several differences between younger and elderly osteoarthritis patients [26-28]: Osteoarthritis is based on a continuous degenerative process that is therefore more pronounced in advanced ages. In turn, the proportion of patients with posttraumatic secondary osteoarthritis is lower in elderly patients. Elderly

Table 1 Patient and treatment characteristics of the study cohort $(n=1185$ joints $)$

\begin{tabular}{|c|c|c|c|}
\hline & & \multicolumn{2}{|c|}{ Median (range) } \\
\hline \multicolumn{2}{|c|}{ Age at radiotherapy (years) } & \multicolumn{2}{|c|}{$76(65-98)$} \\
\hline \multicolumn{2}{|c|}{ Body mass index $\left(\mathrm{kg} / \mathrm{m}^{2}\right), n=270$} & \multicolumn{2}{|c|}{$27.7(16.0-52.1)$} \\
\hline & & $n$ & $\%$ \\
\hline \multirow[t]{3}{*}{ Age groups } & $65-74$ years & 544 & 45.9 \\
\hline & $75-84$ years & 507 & 42.8 \\
\hline & $\geq 85$ years & 134 & 11.3 \\
\hline \multirow[t]{2}{*}{ Gender } & Male & 327 & 27.6 \\
\hline & Female & 858 & 72.4 \\
\hline \multirow[t]{6}{*}{ Location } & Hand & 363 & 30.6 \\
\hline & Shoulder & 147 & 12.4 \\
\hline & Hip & 33 & 2.8 \\
\hline & Knee & 419 & 35.4 \\
\hline & Foot & 219 & 18.5 \\
\hline & Others & 4 & 0.3 \\
\hline \multirow{2}{*}{$\begin{array}{l}\text { Previous } \\
\text { therapeutic } \\
\text { measures }\end{array}$} & NSAIDs & 733 & 61.9 \\
\hline & $\begin{array}{l}\text { Intraarticular corticosteroid } \\
\text { injection }\end{array}$ & 221 & 18.6 \\
\hline \multirow{3}{*}{$\begin{array}{l}\text { Radiotherapy } \\
\text { fractionation }\end{array}$} & $6 \times 0.5 \mathrm{~Gy}$ & 257 & 21.7 \\
\hline & $6 \times 1 \mathrm{~Gy}$ & 916 & 77.3 \\
\hline & Others & 12 & 1.0 \\
\hline
\end{tabular}

patients exhibit a different pain perception than younger patients, and the duration of osteoarthritis-related pain generally is longer in elderly patients [26-28]. A previous prospective trial reported beneficial effects of low-dose radiotherapy in elderly patients with painful skeletal disorders; however, patients with osteoarthritis of the hands or the shoulder were not included in the study [29].

We therefore aimed to analyze the effects of linear accelerator-based low-dose radiotherapy in a large cohort of elderly osteoarthritis patients treated at two university hospitals.

\section{Material and methods}

\section{Treatment}

The Independent Ethics Committees of University of Freiburg (reference no. 150/20) and University of Heidelberg (reference no. S-040/2018) approved this study. Patients who received low-dose radiotherapy for osteoarthritis between 2008 and 2020 and were $\geq 65$ years at the time of radiotherapy were included. Low-dose radiotherapy was applied for painful osteoarthritis of the large joints, i.e., the knees, hips and shoulders, as well as the small joints, i.e., the wrist, fingers, thumbs, ankle, and feet, following the guidelines of the German Society of Radiation Oncology [30]. Radiotherapy was regularly performed in 6 fractions with single doses of 0.5 or $1 \mathrm{~Gy}$ that were given twice or thrice weekly. All patients received low-dose photon radiotherapy using a linear accelerator either after computed tomography (CT)-based 3-dimensional treatment planning or after treatment simulation using 2-dimensional X-ray imaging. Initial pain intensity prior to treatment (t0) as quantified by the numerical rating scale (NRS) and preceding therapeutic procedures such as NSAID intake or intraarticular corticosteroid injections were extracted from the patient records. Initial pain response immediately after radiotherapy ( $\mathrm{t} 1$ ) was accessible for all patients using the Pannewitz score ranging from 0 (complete pain relief) to 4 (worsening of pain). As the retrospective data did not always allow to differentiate between the Pannewitz score 1 (major pain relief) and 2 (minor pain relief), we summarized both score points. Patients were invited for a follow-up consultation at about 8 weeks after completion of radiotherapy $(\mathrm{t} 2)$, and in case of inadequate response or recurrent pain, a second radiotherapy course was discussed with the patients.

\section{Statistical analysis}

Wilcoxon signed-rank tests were used to compare NRS values between the time points. Mann-Whitney U (2 groups) 


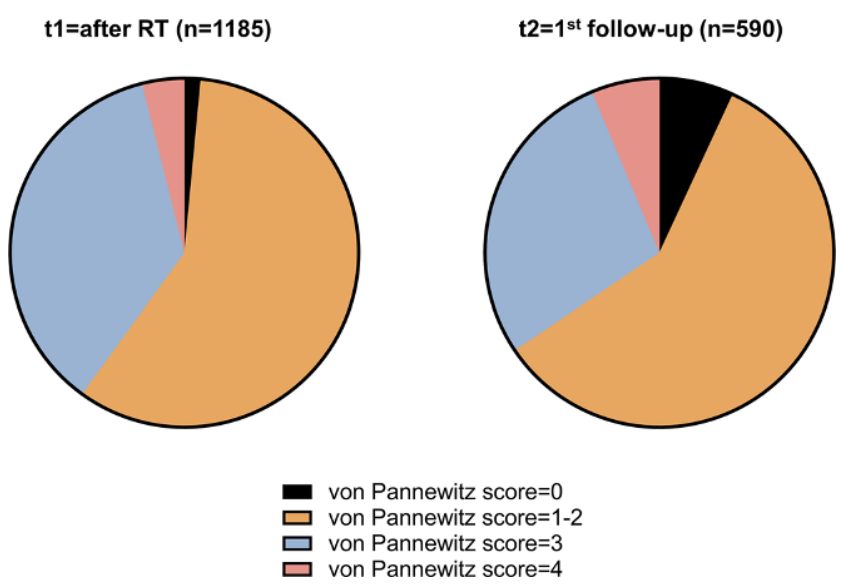

Fig. 1 Two-thirds of elderly patients exhibit pain improvements after low-dose radiotherapy (RT) for osteoarthritis. Pie chart showing the distribution of the Pannewitz score at $\mathrm{t} 1$ (after the last radiation fraction) and at $\mathrm{t} 2$ (at the first follow-up)

or Kruskal-Wallis tests ( $\geq 3$ groups) were performed to compare the pain response measured by the Pannewitz score. A $\chi^{2}$ test was performed to examine whether the re-irradiation rate was different between the age groups. Statistical significance was assumed for $p<0.05$. IBM SPSS Statistics software version 25 (IBM, Armonk, NY, USA) and GraphPad Prism software version 8 (GraphPad Software, San Diego, CA, USA) were used for statistical analyses.

\section{Results}

\section{Patient and treatment characteristics}

A total of 970 patients with 1185 treated lesions were analyzed. As some patients were treated for separate joints at different time points, patient characteristics are related to the total number of sites (Table 1). Median age of our elderly cohort was 76 years (range 65-98 years), and almost three quarters of patients were female $(n=858,72.4 \%)$. Median body mass index (BMI) was assessable for 270 patients and amounted to $27.7 \mathrm{~kg} / \mathrm{m}^{2}$ (range $16.0-52.1 \mathrm{~kg} / \mathrm{m}^{2}$ ). Most common treatment sites included knees $(n=419,35.4 \%)$, hands $(n=363,30.6 \%)$, and feet $(n=219,18.5 \%)$. The majority of patients were treated with NSAIDs prior to radiotherapy $(n=733,61.9 \%)$, and a considerable percentage of patients had also received prior intraarticular corticosteroid injections $(n=221,18.6 \%)$. The most common treatment scheme was $6 \times 1 \mathrm{~Gy}(n=916,77.3 \%)$, while $6 \times 0.5 \mathrm{~Gy}$ was less frequently used $(n=257,21.7 \%)$.

\section{Pain response}

Directly upon completion of low-dose radiotherapy, 18 patients $(1.5 \%)$ exhibited a complete pain relief (Pannewitz score $=0), 693(58.5 \%)$ reported a partial response (Pannewitz score $=1-2), 428(36.1 \%)$ unaltered pain (Pannewitz score $=3)$, and $46(3.9 \%)$ increases in pain, therefore resulting in a response rate (Pannewitz score $0-2$ ) of $60.0 \%$ at $\mathrm{t} 1$ (Fig. 1). In all, 590 patients (49.8\%) presented for the first follow-up consultation or filled out paper-based pain questionnaires (t2): 387 patients (65.6\%) had a pain response, whereas 203 patients $(34.4 \%)$ reported no pain response. Of these 203 patients, 166 patients (28.1\%) exhibited stable pain and $37(6.3 \%)$ showed increases in pain intensity. Mean NRS was $66.0( \pm 11.1)$ prior to radiotherapy, 53.4 $( \pm 18.0)$ at $\mathrm{t} 1$ and $44.5( \pm 23.7)$ at $\mathrm{t} 2(p<0.001$ for $\mathrm{t} 0-\mathrm{t} 1$, $\mathrm{t} 1-\mathrm{t} 2$ and $\mathrm{t} 0-\mathrm{t} 2$, Wilcoxon signed-rank test). By only analyzing patients with information at $\mathrm{t} 0, \mathrm{t} 1$, and $\mathrm{t} 2$, the mean NRS difference amounted to $-12.3( \pm 15.4)$ between t0 and $\mathrm{t} 1$ and $-21.0( \pm 23.9)$ between $\mathrm{t} 0$ and $\mathrm{t} 2$.

Following a common subdivision approach for the elderly population, we divided our cohort into young olds (65-74 years), older olds (75-84 years), and oldest olds ( $\geq 85$ years) and compared pain response rates among the three age groups (Fig. 2). Initial mean NRS values were comparable and ranged at $66.1,65.9$, and 65.5 for young olds, older olds, and oldest olds, respectively $(p=0.759$, Kruskal-Wallis test). Both at $\mathrm{t} 1$ and $\mathrm{t} 2$, there were no significant differences regarding patients' NRS between the different age groups (t1: $p=0.467, \mathrm{t} 2: p=0.477)$. Similarly, the Pannewitz score was found to be similar between the different age groups of elderly osteoarthritis patients: 6 (1.1\%), 325 (59.7\%), 195 (35.8\%), and 18 (3.3\%) young old patients exhibited Pannewitz scores of $0,1-2,3$, and 4, respectively at $\mathrm{t} 1$. This was comparable to the distribution in the older olds $(2.2 \%$ with Pannewitz $=0,58.8 \%$ with Pannewitz $=1-2,34.9 \%$ with Pannewitz $=3$, and $4.1 \%$ with Pannewitz $=4)$ and oldest olds $(0.7 \%$ with Pannewitz $=0$, 52.2\% with Pannewitz $=1-2,41.8 \%$ with Pannewitz $=3$, and $5.2 \%$ with Pannewitz $=4)(p=0.172$, Kruskal-Wallis test). At t2, there also were no significant differences regarding Pannewitz scores between the three age groups $(p=0.684)$. The overall pain response rates (Pannewitz score $=0-2)$ at $\mathrm{t} 2$ were $68.0 \%, 64.0 \%, 61.5 \%$ for the young olds, older olds, and oldest olds, respectively.

We furthermore analyzed the role of patient gender, radiotherapy fractionation, and osteoarthritis location on the pain response (Fig. 3). Prior to radiotherapy, female patients had higher NRS values than male patients $(66.9$ versus 63.6, $p<0.001$, Mann-Whitney $\mathrm{U}$ test). However, there were no differences in the mean NRS decline between male and female patients at $\mathrm{t} 1(p=0.271)$ or $\mathrm{t} 2(p=0.610)$. As shown in previous prospective trials for other benign 


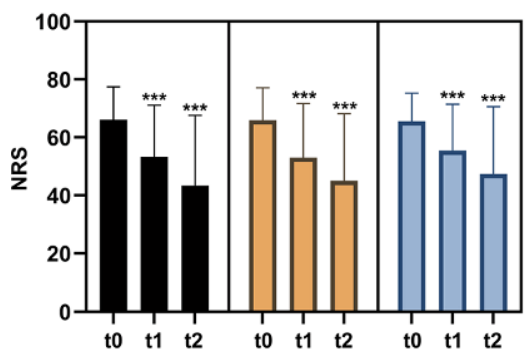

b

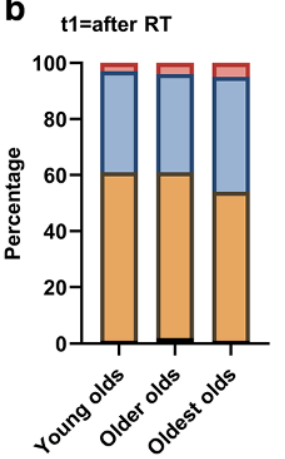

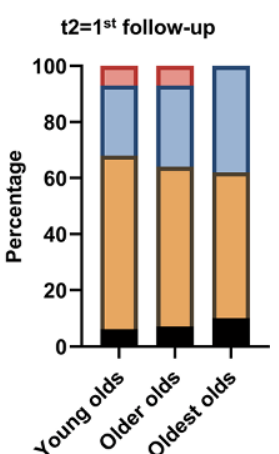

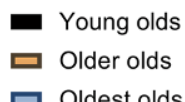

Fig. 2 Pain response is not dependent on patient's age in elderly patients with painful osteoarthritis. a Mean numerical rating scale (NRS) values with the according standard deviation are shown for the three age groups (young olds $=65-74$ years, older olds $=75-84$ years, oldest olds $=85$ years and older) at the different time points. T0 $=$ NRS prior to radiotherapy $(\mathrm{RT}), \mathrm{t} 1=\mathrm{NRS}$ at the last radiation fraction, $\mathrm{t} 2=\mathrm{NRS}$ at the first followup. Wilcoxon signed-rank tests were used to compare $\mathrm{t} 1$ with $\mathrm{t} 0$ and $\mathrm{t} 2$ with $\mathrm{t} 0$. $* * * p<0.001$. b Pannewitz scores at $\mathrm{t} 1$ and $\mathrm{t} 2$ in dependence of patient's age. Kruskal-Wallis tests did not reveal significant differences regarding the Pannewitz score between the different age groups

diseases, there was no difference in the analgesic efficacy between single doses of $1 \mathrm{~Gy}$ and $0.5 \mathrm{~Gy}(\mathrm{t} 1: p=0.313$, $\mathrm{t} 2$ : $p=0.178$, Mann-Whitney $\mathrm{U}$ test) [31-33]. The different osteoarthritis sites in our study showed similar NRS dynamics both at $\mathrm{t} 1$ and at $\mathrm{t} 2$ with no differences between the groups $(\mathrm{t} 1: p=0.970, \mathrm{t} 2: p=0.192$, Kruskal-Wallis test). Neither at t1 ( $p=0.336$, Mann-Whitney U test) nor at $\mathrm{t} 2(p=0.380)$, patients with previous NSAID intake had a different pain response as indicated in the Pannewitz score distribution. Similarly, previous intra-articular corticosteroid administration had no effect on patients' pain response ( $\mathrm{t} 1: p=0.361, \mathrm{t} 2: p=0.273)$. Patients with obesity $\left(\mathrm{BMI}>25 \mathrm{~kg} / \mathrm{m}^{2}\right)$ exhibited similar NRS declines both at t1 $(-10.9$ versus $-9.4, p=0.412)$ and at $\mathrm{t} 2(-20.6$ versus $-21.0, p=0.690)$ compared to patients of normal weight.
Likewise, pain responses as measured with the Pannewitz score were not different between overweight and normalweight individuals ( $\mathrm{t} 1: p=0.970, \mathrm{t} 2: p=0.617$ ).

\section{Second radiotherapy course}

We also investigated whether there were differences in the frequency of second radiotherapy courses depending on patient age. A total of $384 \mathrm{~s}$ radiotherapy courses $(32.4 \%)$ were applied in our cohort. Re-irradiation rates did not differ between the different age groups and amounted to $33.3 \%$ in the young olds, $32.0 \%$ in the older olds, and $30.6 \%$ in the oldest olds ( $p=0.805, \chi^{2}$ test; Fig. 4 ). In a total of 351 treated sites, pain response could be assessed at the end of the second radiotherapy course ( $\mathrm{t} 3$ ). At $\mathrm{t} 3$, complete pain re- a

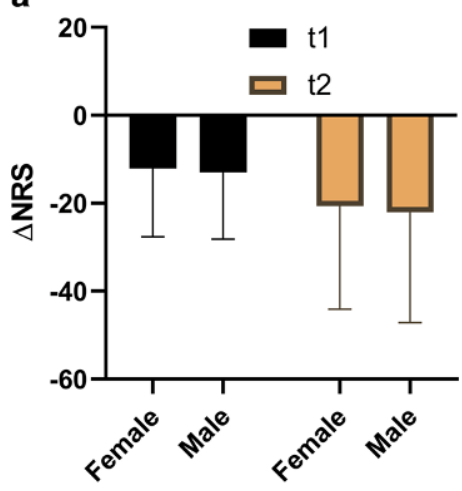

b

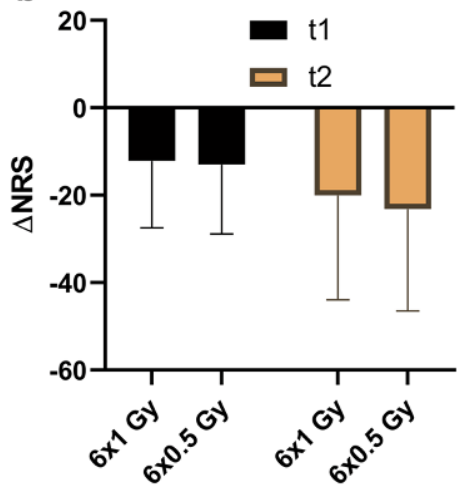

C

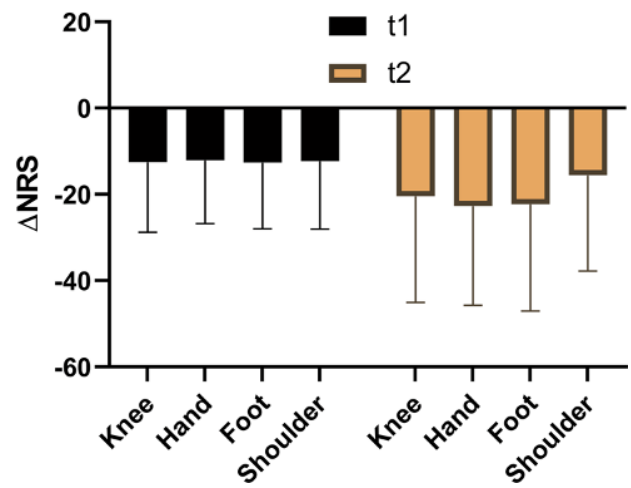

Fig. 3 Low-dose radiotherapy reduces pain intensity irrespectively of gender, fractionation and joint location in the elderly. Pain response $\Delta$ NRS at $\mathrm{t} 1$ = immediately upon radiotherapy completion and $\mathrm{t} 2=$ first follow-up consultation compared to baseline NRS value in dependence of gender (a), radiotherapy fractionation (b) or osteoarthritis location (c). NRS numerical rating scale 
lief (Pannewitz score $=0$ ) was found in 5 cases $(1.4 \%)$, partial response (Pannewitz score $=1-2$ ) in 220 cases $(62.7 \%$ ), stable pain (Pannewitz score $=3$ ) in 119 cases $(33.9 \%)$, and worse pain (Pannewitz score $=4$ ) in 7 cases $(2.0 \%)$. Again, there were no differences in the Pannewitz score distribution between the three age groups $(p=0.256$, Kruskal-Wallis test). At the first follow-up after the second course (t4, $n=195$ ), Pannewitz score distribution was similar to $\mathrm{t} 3$ : $3.6 \%$ of patients had a Pannewitz score $=0,57.4 \%$ a Pannewitz score $=1-2,36.4 \%$ a Pannewitz score $=3$, and $2.6 \%$ a Pannewitz score $=4$, leading to a pain response rate of $61.0 \%$ after re-irradiation that was comparable between the age groups ( $p=0.535$, Kruskal-Wallis test).

\section{Discussion}

We demonstrated in a large multicenter cohort including 970 elderly patients with 1185 treated sites that low-dose radiotherapy is an analgesic treatment for painful osteoarthritis irrespectively of patient age. Our study is, to the best of our knowledge, the largest study of elderly osteoarthritis patients receiving low-dose radiotherapy. We did not observe differences regarding the NRS or the Pannewitz score dynamics between young old, older old, and oldest old pa- tients, showing that low-dose radiotherapy does not lose efficacy in patients with very advanced age.

Considering that very old patients have a higher risk for toxicities from long-term NSAID intake (e.g., gastrointestinal bleeding [34]), low-dose radiotherapy can be considered as appropriate alternative for elderly osteoarthritis patients. Furthermore, very old osteoarthritis patients bear a considerably reduced carcinogenic risk after low-dose radiotherapy considering the proposed latency time of solid cancer induction. The overall pain response rate at the first follow-up appointment in our study was $65.6 \%$ which is in the range or slightly lower than reported in previously published studies in which a case-related average of $77.7 \%$ pain response was reported [24]. Furthermore, the re-irradiation rate in our cohort amounted to $32.4 \%$ which is comparable to the $30 \%$ rate reported in a German patterns-of-care study for painful knee osteoarthritis [9]. Compared to other studies, the average age of 76 years in our cohort was considerably higher (e.g., Hautmann et al.: 65 years [24], Micke et al.: 63 years [23], Keilholz et al.: 64 years [35], Minten et al.: 65 years [36], Kaltenborn et al.: 62 years [37]). Importantly, we could not find subgroups of elderly patients that benefitted less from low-dose radiotherapy, and neither gender, fractionation, joint location, previous NSAID administration, intra-articular corticosteroid injections, nor BMI influenced pain response rates. a

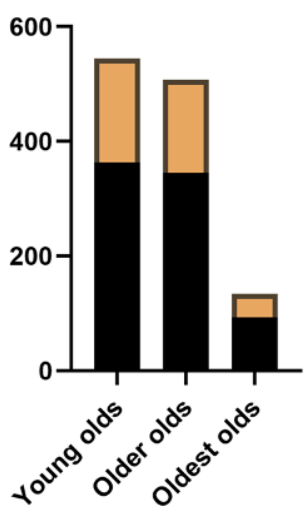

2nd course

- No 2nd course b

t3=after $2 n d$ course $(n=351)$
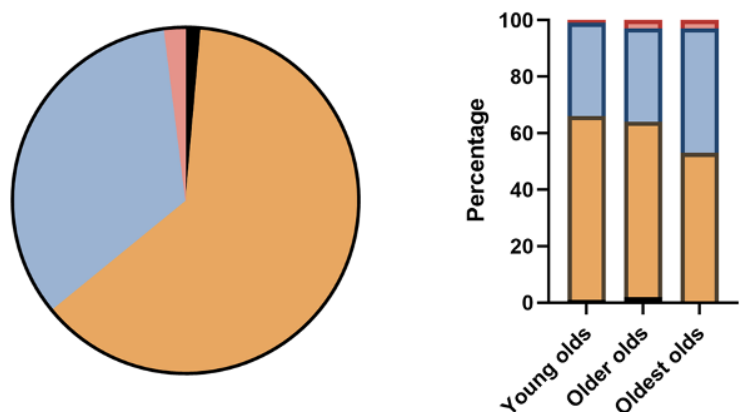

von Pannewitz score $=0$ $\square$ von Pannewitz score=1-2 $\square$ von Pannewitz score $=3$ $\square$ von Pannewitz score=4

C

t4=1 ${ }^{\text {st }}$ follow-up after $2 n d$ course $(n=195)$
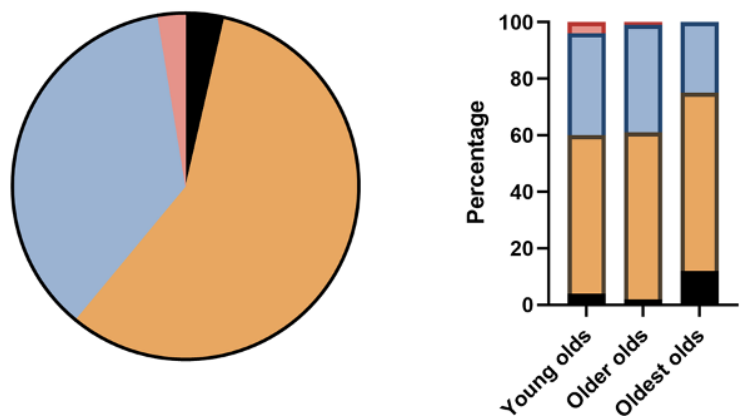

von Pannewitz score $=0$ $\square$ von Pannewitz score=1-2 $\square$ von Pannewitz score=3 $\square$ von Pannewitz score=4

Fig. 4 Second courses of low-dose radiotherapy result in still favorable pain response rates in the elderly. a Frequency of re-irradiation in the young olds (65-74 years), older olds ( $75-84$ years), and oldest olds ( $\geq 85$ years). b Pain response determined by the Pannewitz score at $t 3=$ the last fraction of the second course. $\mathbf{c}$ Pannewitz score distribution at $\mathrm{t} 4=$ first follow-up after re-irradiation 
Although a placebo effect cannot be ruled out, it should be considered that low-dose radiotherapy is commonly applied for patients after multiple previous therapy attempts, therefore considering a rather intensively pretreated patient cohort with a long disease history. Increasing pain response rates between $\mathrm{t} 1$ and $\mathrm{t} 2$, as seen in our study, would also rather be untypical for a pure placebo effect. It may further be hypothesized that elderly patients with favorable pain response after low-dose radiotherapy would rather omit the follow-up consultation at $\mathrm{t} 2$, thereby biasing the results towards lower pain response rates. In turn, patients that exhibit equal or even more intense pain after radiotherapy could be maybe more likely to keep the appointment at the follow-up consultation to receive a second course.

Although low-dose radiotherapy is a widely used treatment modality for osteoarthritis in central and Eastern Europe and numerous retrospective analyses have demonstrated the pain-relieving effects of this therapy, two randomized, double-blind, sham-controlled studies could not confirm superior analgesic effects of low-dose radiotherapy for knee and hand osteoarthritis compared with sham treatment [36, 38]. However, low patient numbers, an inadequate power to detect moderate benefits, short followup times, imbalances in the treatment groups, and the inclusion of patients with severe pain and long histories of chronic pain suggesting already advanced joint degeneration are considered as limitations of these studies [39]. Older randomized trials had similarly short follow-up times and included indications such as intercostal neuralgia and spondylitis which no longer constitute indications for lowdose radiotherapy [40, 41]. Therefore, there is an urgent need for adequately designed high-quality randomized controlled trials with sufficient patient numbers and followup times as well as an appropriate patient selection in order to improve the evidence for low-dose radiotherapy of osteoarthritis [42].

Although providing real-world data of low-dose radiotherapy for painful osteoarthritis in a large cohort of elderly patients, our analysis has limitations: For instance, about half of patients failed to present for the first followup appointment; therefore, information on patient's pain intensity at $\mathrm{t} 2$ of these patients are missing. Second, we had insufficient data about patients' long-term pain response, as patients were not routinely re-assessed over the following years. However, previous analyses rather have shown that pain response is augmented with increasing duration and that the full analgesic effect of low-dose radiotherapy is most pronounced at later time points [43].

\section{Conclusion}

To the best of our knowledge, this is the largest study of elderly osteoarthritis patients treated by low-dose radiotherapy. Our data demonstrate that low-dose radiotherapy is an effective treatment in elderly patients with osteoarthritis, resulting in pain improvement in two of three cases. As we could not detect reduced analgesic efficacy in the older/ oldest old patients, our data suggest that there is no upper age limit for radiotherapy. As the risk for tumor induction is decreasing with advancing age, low-dose radiotherapy may even have a more prominent role in this population.

Acknowledgements Alexander Rühle was supported by the IMMPACT-Program for Clinician Scientists, Department of Medicine II, Medical Center-University of Freiburg and Faculty of Medicine, University of Freiburg, funded by the Deutsche Forschungsgemeinschaft (DFG, German Research Foundation)—413517907.

Funding This research did not receive any specific grant from funding agencies in the public, commercial, or not-for-profit sectors.

Author Contribution A.R., T.S., N.H.N.: Study conception and study design. A.R., E.T., R.M., T.S., N.H.N.: Data acquisition, data analysis and data interpretation. A.R., N.H.N.: Statistical analysis, manuscript preparation, manuscript editing. A.R., E.T., R.M., E.H., S.S., C.Z., P.E.H., J.D., A.L.G., T.S., N.H.N.: Manuscript reviewed.

Funding Open Access funding enabled and organized by Projekt DEAL.

\section{Declarations}

Conflict of interest A. Rühle, E. Tkotsch, R. Mravlag, E. Haehl, S.K.B. Spohn, C. Zamboglou, P.E. Huber, J. Debus, A.-L. Grosu, T. Sprave and N.H. Nicolay declare that they have no competing interests.

Ethical standards The study was approved by the institutional ethical review committees in advance (Heidelberg: S-040/2018, Freiburg: $150 / 20)$.

Open Access This article is licensed under a Creative Commons Attribution 4.0 International License, which permits use, sharing, adaptation, distribution and reproduction in any medium or format, as long as you give appropriate credit to the original author(s) and the source, provide a link to the Creative Commons licence, and indicate if changes were made. The images or other third party material in this article are included in the article's Creative Commons licence, unless indicated otherwise in a credit line to the material. If material is not included in the article's Creative Commons licence and your intended use is not permitted by statutory regulation or exceeds the permitted use, you will need to obtain permission directly from the copyright holder. To view a copy of this licence, visit http://creativecommons.org/licenses/by/4. $0 /$.

\section{References}

1. Zhang Y, Jordan JM (2010) Epidemiology of osteoarthritis. Clin Geriatr Med 26:355-369 
2. Michael JW-P, Schlüter-Brust KU, Eysel P (2010) The epidemiology, etiology, diagnosis, and treatment of osteoarthritis of the knee. Dtsch Arztebl Int 107:152-162

3. Felson DT (1988) Epidemiology of hip and knee osteoarthritis. Epidemiol Rev 10:1-28

4. Turkiewicz A, Petersson IF, Björk J et al (2014) Current and future impact of osteoarthritis on health care: a population-based study with projections to year 2032. Osteoarthritis Cartilage 22:1826-1832

5. Hopman-Rock M, Odding E, Hofman A, Kraaimaat FW, Bijlsma JW (1996) Physical and psychosocial disability in elderly subjects in relation to pain in the hip and/or knee. J Rheumatol 23:1037-1044

6. Alamanda VK, Wally MK, Seymour RB, Springer BD, Hsu JR (2020) Prevalence of opioid and benzodiazepine prescriptions for osteoarthritis. Arthritis Care Res 72:1081-1086

7. Hall AJ, Stubbs B, Mamas MA, Myint PK, Smith TO (2016) Association between osteoarthritis and cardiovascular disease: systematic review and meta-analysis. Eur J Prev Cardiol 23:938-946

8. Sinusas K (2012) Osteoarthritis: diagnosis and treatment. Am Fam Physician 85:49-56

9. Mücke R, Seegenschmiedt MH, Heyd R et al (2010) Strahlentherapie bei schmerzhafter Kniegelenkarthrose (Gonarthrose). Strahlenther Onkol 186:7-17

10. Zwicker F, Kirchner C, Huber PE, Debus J, Zwicker H, Klepper R (2019) Breast cancer occurrence after low dose radiotherapy of nonmalignant disorders of the shoulder. Sci Rep 9:5301

11. Reichl B, Block A, Schäfer U et al (2015) DEGRO practical guidelines for radiotherapy of non-malignant disorders. Part I: physical principles, radiobiological mechanisms, and radiogenic risk. Strahlenther Onkol 191:701-709

12. Rödel F, Keilholz L, Herrmann M, Sauer R, Hildebrandt G (2007) Radiobiological mechanisms in inflammatory diseases of low-dose radiation therapy. Int J Radiat Biol 83:357-366

13. Lödermann B, Wunderlich R, Frey $S$ et al (2012) Low dose ionising radiation leads to a NF- $\kappa \mathrm{B}$ dependent decreased secretion of active IL- $1 \beta$ by activated macrophages with a discontinuous dosedependency. Int J Radiat Biol 88:727-734

14. Rödel F, Hofmann D, Auer J et al (2008) The anti-inflammatory effect of low-dose radiation therapy involves a diminished CCL20 chemokine expression and granulocyte/endothelial cell adhesion. Strahlenther Onkol 184:41-47

15. Hildebrandt G, Radlingmayr A, Rosenthal S et al (2003) Low-dose radiotherapy (LD-RT) and the modulation of iNOS expression in adjuvant-induced arthritis in rats. Int J Radiat Biol 79:993-1001

16. Hildebrandt G, Maggiorella L, Rödel F, Rödel V, Willis D, Trott KR (2002) Mononuclear cell adhesion and cell adhesion molecule liberation after X-irradiation of activated endothelial cells in vitro. Int J Radiat Biol 78:315-325

17. Deloch L, Derer A, Hueber AJ et al (2018) Low-dose radiotherapy ameliorates advanced arthritis in hTNF- $\alpha$ tg mice by particularly positively impacting on bone metabolism. Front Immunol 9:1834

18. Hautmann MG, Hipp M, Neumaier U et al (2020) Radiotherapy for osteoarthritis of the ankle and tarsal joints - analysis of 66 joints. Strahlenther Onkol 196:569-575

19. Keller S, Müller K, Kortmann RD et al (2013) Efficacy of low-dose radiotherapy in painful gonarthritis: experiences from a retrospective East German bicenter study. Radiat Oncol 8:29

20. Rogers S, Eberle B, Vogt DR et al (2020) Prospective evaluation of changes in pain levels, quality of life and functionality after low dose radiotherapy for epicondylitis, plantar fasciitis, and finger osteoarthritis. Front Med (Lausanne) 7:195

21. Donaubauer AJ, Zhou JG, Ott OJ et al (2020) Low dose radiation therapy, particularly with $0.5 \mathrm{~Gy}$, improves pain in degenerative joint disease of the fingers: results of a retrospective analysis. Int $\mathrm{J}$ Mol Sci 21(16):5854
22. Hautmann MG, Rechner P, Hipp M et al (2019) Re-irradiation for osteoarthritis-retrospective analysis of 217 joints. Strahlenther Onkol 195:1060-1067

23. Micke O, Ugrak E, Bartmann S et al (2018) Radiotherapy for calcaneodynia, achillodynia, painful gonarthrosis, bursitis trochanterica, and painful shoulder syndrome-early and late results of a prospective clinical quality assessment. Radiat Oncol 13:71

24. Hautmann MG, Rechner P, Neumaier U et al (2020) Radiotherapy for osteoarthritis - an analysis of 295 joints treated with a linear accelerator. Strahlenther Onkol 196:715-724

25. Ott OJ, Hertel S, Gaipl US, Frey B, Schmidt M, Fietkau R (2014) The Erlangen Dose Optimization trial for radiotherapy of benign painful shoulder syndrome. Long-term results. Strahlenther Onkol 190:394-398

26. Fitzcharles M-A, Lussier D, Shir Y (2010) Management of chronic arthritis pain in the elderly. Drugs Aging 27:471-490

27. Roos EM (2005) Joint injury causes knee osteoarthritis in young adults. Curr Opin Rheumatol 17:195-200

28. Hernández L, Terradas M, Camps J, Martín M, Tusell L, Genescà A (2015) Aging and radiation: bad companions. Aging Cell 14:153-161

29. Micke O, Seegenschmiedt MH, Adamietz IA et al (2017) Lowdose radiation therapy for benign painful skeletal disorders: the typical treatment for the elderly patient? Int J Radiat Oncol Biol Phys 98:958-963

30. Ott OJ, Niewald M, Weitmann HD et al (2015) DEGRO guidelines for the radiotherapy of non-malignant disorders. Part II: painful degenerative skeletal disorders. Strahlenther Onkol 191:1-6

31. Ott OJ, Jeremias C, Gaipl US, Frey B, Schmidt M, Fietkau R (2013) Radiotherapy for achillodynia: results of a single-center prospective randomized dose-optimization trial. Strahlenther Onkol 189:142-146

32. Ott OJ, Hertel S, Gaipl US, Frey B, Schmidt M, Fietkau R (2014) The Erlangen Dose Optimization trial for low-dose radiotherapy of benign painful elbow syndrome. Long-term results. Strahlenther Onkol 190:293-297

33. Ott OJ, Jeremias C, Gaipl US, Frey B, Schmidt M, Fietkau R (2014) Radiotherapy for benign calcaneodynia: long-term results of the Erlangen Dose Optimization (EDO) trial. Strahlenther Onkol 190:671-675

34. Shorr RI, Ray WA, Daugherty JR, Griffin MR (1993) Concurrent use of nonsteroidal anti-inflammatory drugs and oral anticoagulants places elderly persons at high risk for hemorrhagic peptic ulcer disease. Arch Intern Med 153:1665-1670

35. Keilholz L, Seegenschmiedt MH, Sauer R (1998) Radiotherapie bei schmerzhaften degenerativ-entzündlichen Gelenkerkrankungen. Strahlenther Onkol 174:243-250

36. Minten MJM, Leseman-Hoogenboom MM, Kloppenburg M et al (2018) Lack of beneficial effects of low-dose radiation therapy on hand osteoarthritis symptoms and inflammation: a randomised, blinded, sham-controlled trial. Osteoarthritis Cartilage 26:1283-1290

37. Kaltenborn A, Bulling E, Nitsche M, Carl UM, Hermann RM (2016) The field size matters: low dose external beam radiotherapy for thumb carpometacarpal osteoarthritis: importance of field size. Strahlenther Onkol 192:582-588

38. Mahler EAM, Minten MJ, Leseman-Hoogenboom MM et al (2019) Effectiveness of low-dose radiation therapy on symptoms in patients with knee osteoarthritis: a randomised, double-blinded, shamcontrolled trial. Ann Rheum Dis 78:83-90

39. Ott OJ, Micke O, Mücke R et al (2019) Low-dose radiotherapy: mayday, mayday. We've been hit! Strahlenther Onkol 195:285-288

40. Valtonen EJ, Lilius HG, Malmio K (1975) The value of roentgen irradiation in the treatment of painful degenerative and inflammatory musculoskeletal conditions. A double-blind study. Scand J Rheumatol 4:247-249 
41. Goldie I, Rosengren B, Moberg E, Hedelin E (1970) Evaluation of radiation treatment of painful conditions of the locomotor system. A double blind study. Acta Radiol Ther Phys Biol 9:311-322

42. Montero A, Sabater S, Rödel F et al (2020) Is it time to redefine the role of low-dose radiotherapy for benign disease? Ann Rheum Dis 79:e34
43. Juniku N, Micke O, Seegenschmiedt MH, Muecke R (2019) Radiotherapy for painful benign skeletal disorders. Strahlenther Onkol 195:1068-1073 